\title{
An assessment of the transient effect on helicopter main rotor stability and power demand
}

ARTICLE INFO

Received: 6 December 2021

Revised: 5 January 2021

Accepted: 14 February 2022

Available online: 5 March 2022

\begin{abstract}
The researched object is a helicopter main rotor with blades of variable geometric twist characteristics. Variable torsion refers to systems of actuators made of shape memory alloys. The presented numerical analyses allow for evaluating both the dynamics of the rotor in transient states, i.e. in the zone between the static phase and the full activation phase and the impact of the change on the pulsation of the amplitude of the necessary power generated by the rotor corresponding the flight state, and thus covering the demand by the disposable power generated by the engine. This study follows a methodology of numerical analyses based on Multi Body Dynamics and the Finite Element Method and uses fluid mechanics elements and algorithms to analyze lift generation, compiled in a single computational environment referring to the same period of time.
\end{abstract}

Key words: propulsion, rotor, power demand, helicopter, transient effect

This is an open access article under the CC BY license (http://creativecommons.org/licenses/BY/4.0/)

\section{Introduction}

The problem of high exhaust emissions $[9,10]$ and energy requirements in aviation [13, 19] have been recently globally studied by researchers. Propulsion systems of light rotorcraft are usually internal combustion engines or electric motors $[9,21,22]$. The application of piston internal combustion engines for aircraft propulsion is associated with the problem of decreasing engine power as a result of increasing flight altitude [4]. The engine powering the aircraft must provide sufficient power supply to allow for flight and operation of on-board instrumentation. There are many ways to reduce power consumption [1]. These include the use of alternative fuels $[3,15]$ or another type of propulsion [5]. Safety considerations play a critical role. Most of essential systems in aircraft are redundant in nature [7].

As new technology and materials are developed, opportunities to reduce power requirements in certain flight states and to increase aircraft range and performance are emerging. Hybrid solutions combining beneficial features of different types of aircraft are known. An example of such objects are gyrocopters which, by combining the phenomenon of auto-rotation with the electric power supply of multi-rotorcraft, enable the optimization of the use of the power in flight [6]. There are also known modifications that give aircraft the possibility of vertical take-off and landing [17]. An interesting issue is also the use of modern construction materials, and more specifically intelligent materials such as shape memory alloys. They make it possible to change geometrical properties of the aircraft. As this is a relatively new issue, it requires a number of studies in aviation.

Shape memory alloys allow interaction with the shape of the aircraft during flight $[2,13]$, but also give the possibility to control the geometry of the main rotor blade $[8$, 12]. The application of shape memory materials to aircraft is itself already a complicated task. It is mainly related to the difficulty of controlling the parameters of material phase transitions and the low repeatability of their operation. Therefore, numerous investigations are carried out in order to better understand the phenomena occurring in smart materials and their influence on the aircraft $[18,20]$. The use of any elements that change the geometry of the blade of the main rotor during its operation leads to the occurrence of a transient state. This situation affects the stability of rotor operation. The power required by the aircraft also changes. The purpose of such modifications is to optimize the operation of the main rotor by minimizing drag and generating the maximum lifting force in the various phases of flight [23].

The application of systems that change the geometry of the aircraft or main rotor blades influences the propulsion unit as well. By reducing the power requirement, it is possible to use an engine with less power and weight, which affects the payload capacity of the aircraft. The energy cost resulting from the use of shape memory materials is the need to power them. This is done by applying voltage or temperature changes $[14,24]$. The aim of research is obviously to apply the technology in such a way that energy consumption in flight is reduced and performance is improved, which will have a positive effect on fuel consumption.

This paper discusses an evaluation of the influence of the transient state on the stability of the rotor operation. Numerical analyses of the phenomena that occur between the static phase and the full activation phase of the shape memory alloy actuator applied to the main rotor blade of a helicopter with a maximum take-off mass of $150 \mathrm{~kg}$ have been performed and described.

\section{Methodology}

Here, a methodology involving numerical analyses based on Multi Body Dynamics and the Finite Element Method was applied. The adopted methodology is based on the strategy of composite analyses using integrated MBD + FEM models as well as analyses related to typical fluid 
mechanics including algorithms of the blade element method and vortex theory. The application of such a combination of algorithms in analysis will allow a realistic assessment of the stability of the rotor in the form of structural dynamics and will also make it possible to assess its impact on the values of rotor thrust force $T$, side forces $\mathrm{S}$ as well as power demand and its harmonic components. The methodology to specify aerodynamic loads is based on algorithms of the Blade Element Method (Fig. 1), while inertial loads are specified from a coupled Multi Body Dynamic model (Fig. 2) in which rigid elements are replaced by susceptible ones in such a way as to reproduce the hub center motion and thus to take into account dynamic features of the rotor.

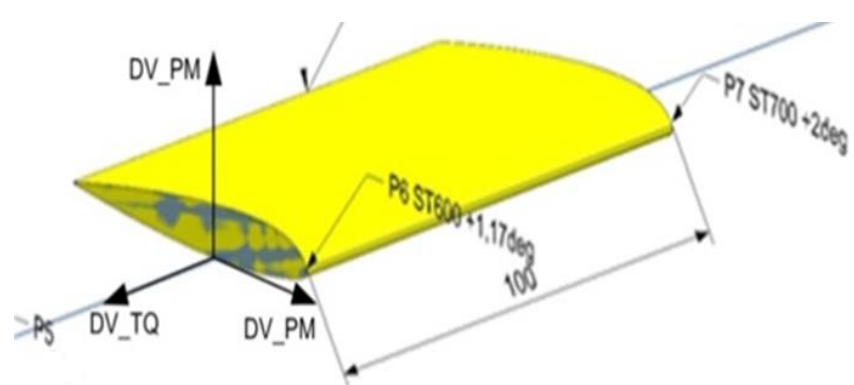

Fig. 1. Profile section intended for the determination of aerodynamic loads

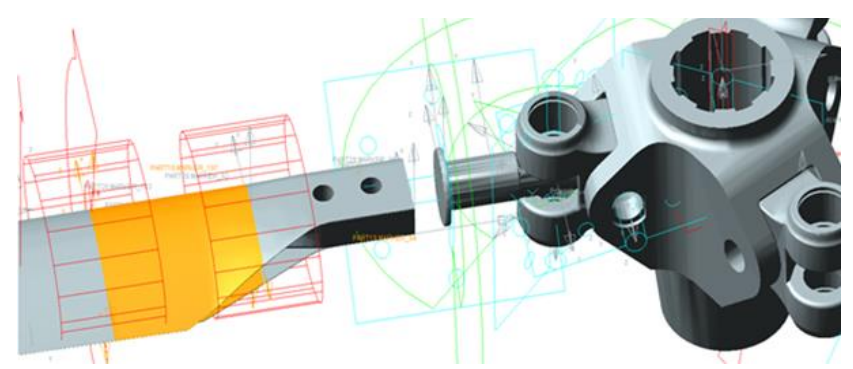

Fig. 2. The inertial system of the MBD model

The integrating element of the calculation process is the MATLAB/ Simulink software environment which controls the process and time step of the calculation (Fig. 3).

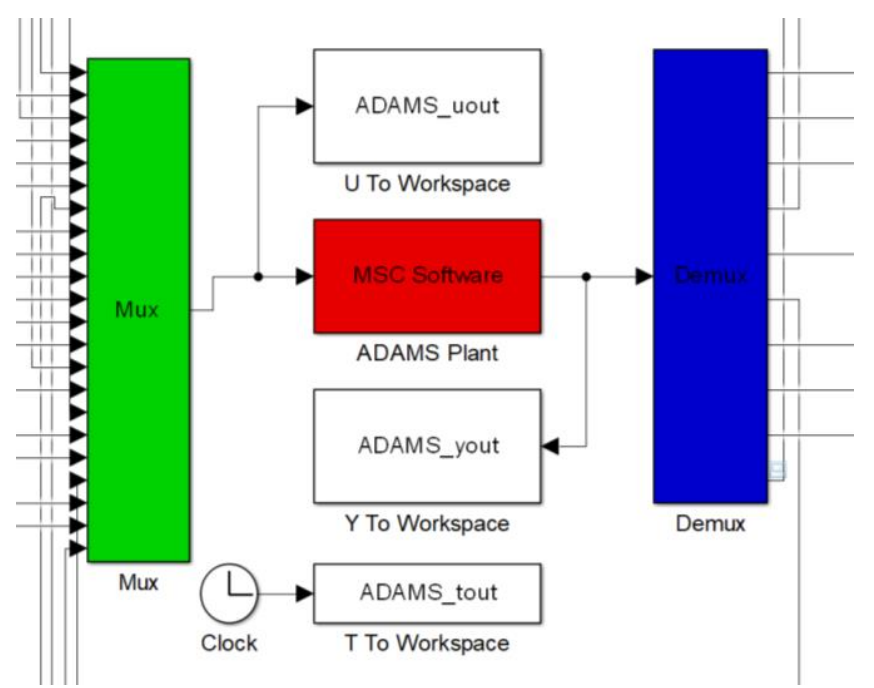

Fig. 3. Matlab/Symulink software integrator diagram

\section{Research object}

The researched object is a helicopter main rotor equipped with blades of variable geometric twist characteristics. The idea of variable twist is based on actuator systems made of shape memory alloys. The blade geometrical twist line is changed by deforming (twisting) the blade on its certain section to obtain a two-phase characteristic of the rotor, characterized by different performance properties that are more optimal for different flight conditions. An important research issue of such a system is the response of the rotor in transition states between the static phase in which the blade retains its original shape and the phase that results from the deformation of the geometric twist line due to the torsional moment load. The calculation model enables the evaluation of selected load components such as torque $\mathrm{Q}$, rotor thrust force $\mathrm{T}$ and side force $\mathrm{S}$.

The characteristic feature of the adopted system of SMA actuators is the dynamics of the process and the rate of shape change which assumes the 10-15 second process of changing the geometry. Compared to actuators based on piezoelectric systems, this period is many times longer, but the cost of adaptation of the actuator is much lower.

The transition time is crucial for rotor stability and thus safety. The expected time of the transition phase depends on the mechanical properties of alloys themselves, the adopted philosophy of providing the required thermal energy and thermal losses associated with this process.

The basis of this methodology is the assessment of rotor efficiency for particular configurations:

- a reference blade, i.e. a blade not activated SMA actuators,

- a blade with a theoretical linear geometric twist,

- a blade with a real twist with non-linear characteristics resulting from activation of the operating elements.

- Figure 4 shows a visualization of the geometric blade twist curves which will be numerically analyzed.

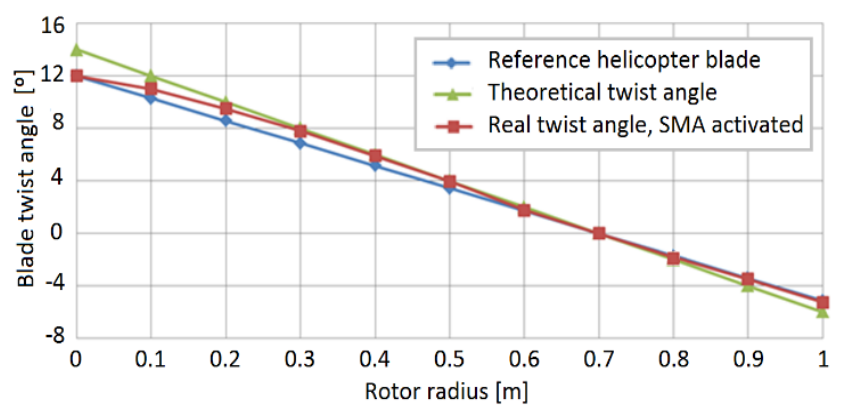

Fig. 4. Geometric blade twist angle

The rotor thrust was analysed for the reference and steady-state twist curves for which the SMA actuators were activated (Fig. 5).

The environment that integrates the analyses and controls the common computational time base is MATLAB/ Simulink using the MBD model integration function. Figure 6 shows a visualization of the base model which undergoes complex analysis. 


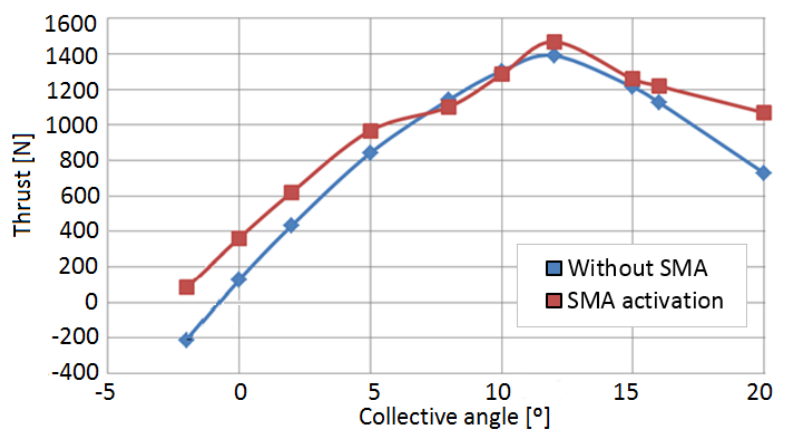

Fig. 5. Rotor thrust



Fig. 6. Visualisation of the MBD main rotor base model

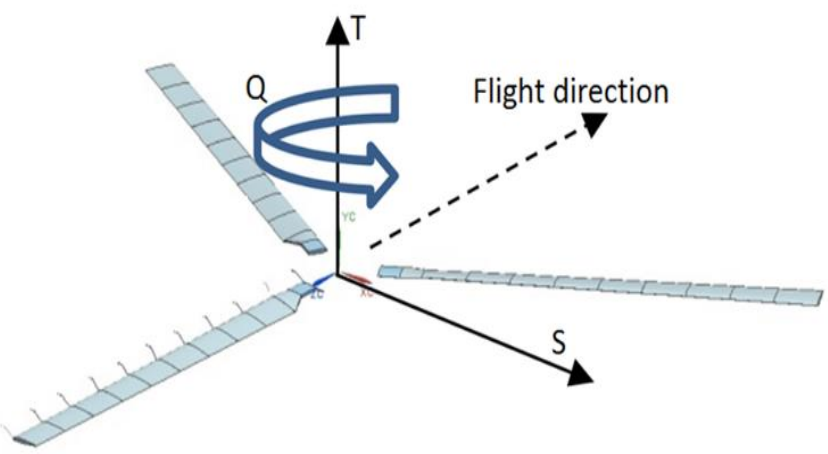

Fig. 7. Visualisation of the load distribution, $\mathrm{T}-$ thrust force, $\mathrm{Q}-$ propulsion torque, $\mathrm{S}$ - side force

The computational model assumes the simplification of rotor blade representation by dividing it into 10 computational sections (Fig. 8), connected by elastic elements with well-defined mass-rigidity properties and well-defined position of the center of gravity in relation to the twist axis. Aerodynamic and inertial loads are applied to the center of gravity of each section, which means that the aerodynamic centers of each section lie on the blade's twist axis.

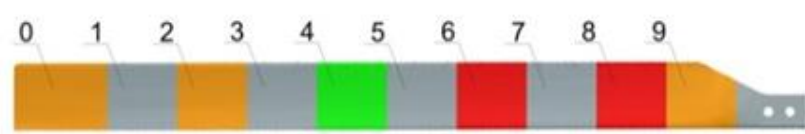

Fig. 8. Blade division into calculation sections
According to the adopted concept, the actuators are activated between sections 8 and 7 , and the actuators are an integral part of the blade and located as near as possible the twist axis. The course of the total twist angle change in the steady state during flight is shown in Fig. 9.

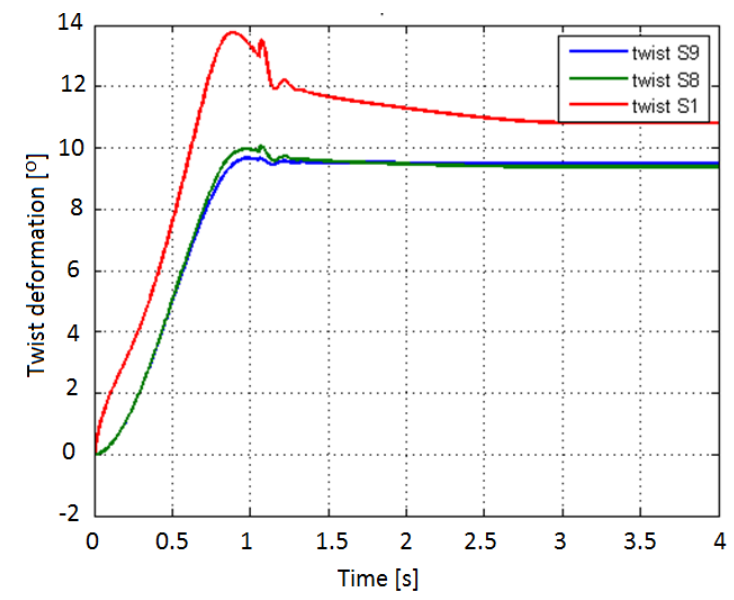

Fig. 9. SMA actuator activation time course

Besides the inertial forces loading the rotor, the main component of forces and moments are aerodynamic loads, determined by CFD analyses both for the individual sections (Fig. 10) and for the whole rotor disc (Fig. 11).

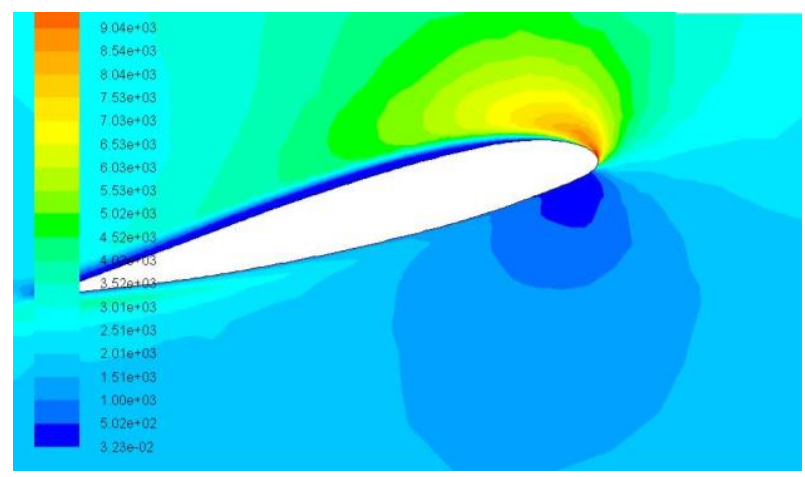

Fig. 10. Results of the CFD analysis of the blade profile section
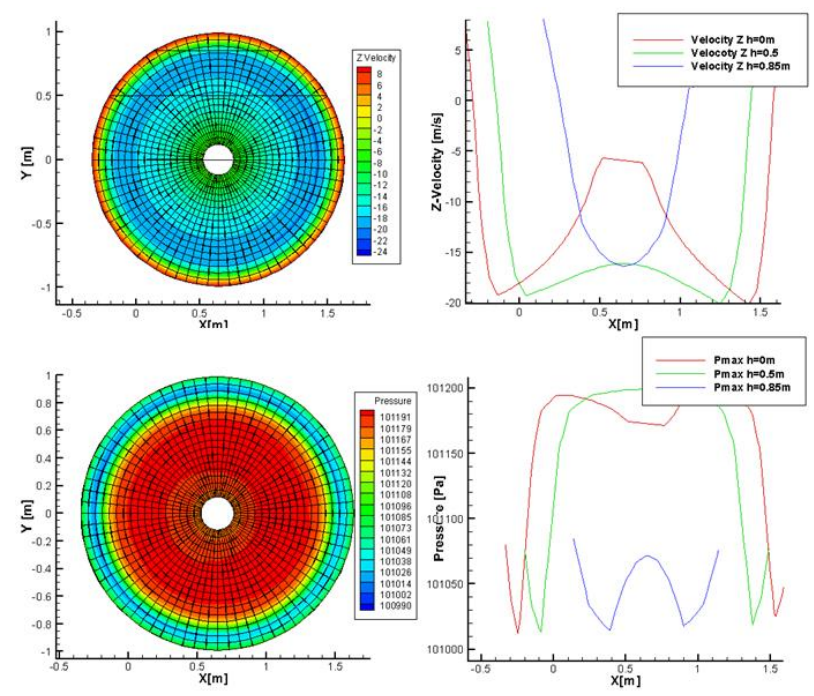

Fig. 11. Rotor disc loads 


\subsection{Analysis}

The analysis covers the assembly of the main rotor loaded with aerodynamic and inertial forces in the steady state, i.e. hovering, and in the transient state when the SMA systems are activated. The analysis consists in comparing the rotational speed pulsations and the power demand necessary during take-off and transition to hovering before and during activation of the actuators. Figure 12 shows a visualization of the rotor start-up and transition to the hovering state.

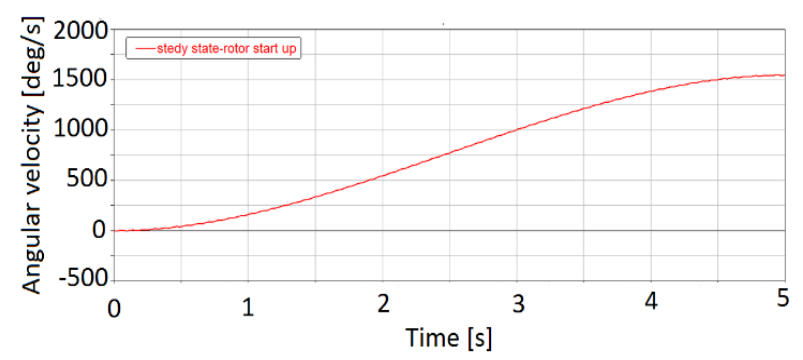

Fig. 12. Rotor speed course during start-up

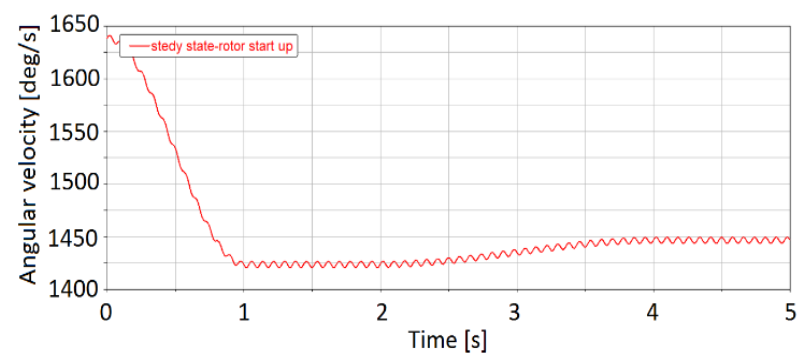

Fig. 13. Rotor lock and hover

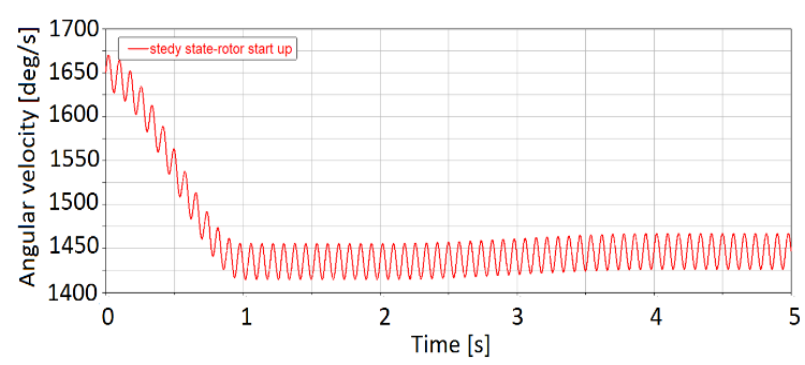

Fig. 14. Rotor lock and hover with SMA activation

The numerical analyses are limited to the transient states of the rotor start-up and transition to hovering. The comparison of the computational cases is limited to the states the SMA actuators are not activated and the case they are fully activated. All analyses were based on standard conditions, i.e. barometric operational altitude $\mathrm{hb}=0 \mathrm{~m}$, ambient temperature compatible with the standard atmosphere OAT = $15^{\circ} \mathrm{C}$.

\section{Results}

The aim of the analyses was to determine the conditions of power demand in states defined as non-stationary. The research enabled us to specify the main components of the power required by the rotor as well as the values of the lateral forces perpendicular to the longitudinal axis of the pylon system of the rotor assembly, bending the shaft at the moment of lock and the transition of the rotor to hovering
(Fig. 15-20). The values and harmonics of the transverse forces determine the stability of the rotor precession axis, while the values of power pulsations are responsible for the assessment of the aerodynamic efficiency of the rotor.

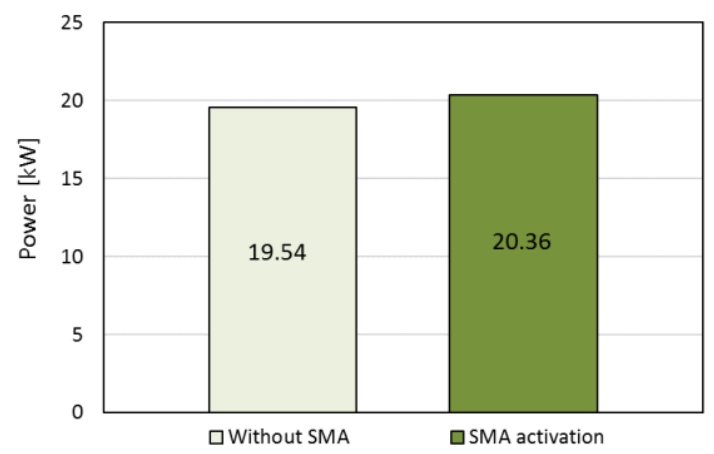

Fig. 15. Average power required for hovering

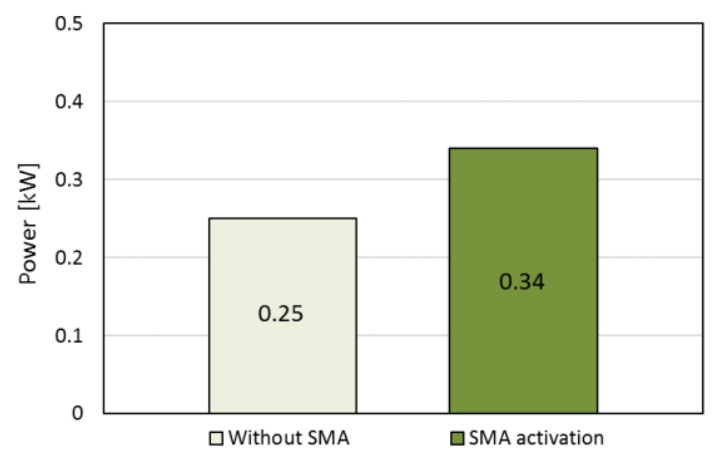

Fig. 16. Harmonics of the power required for hovering - I h power pulsation

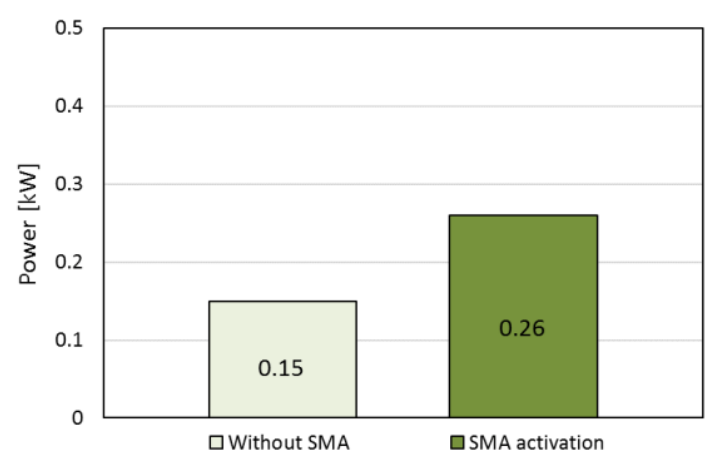

Fig. 17. Harmonics of the power required for hovering - II h power pulsation

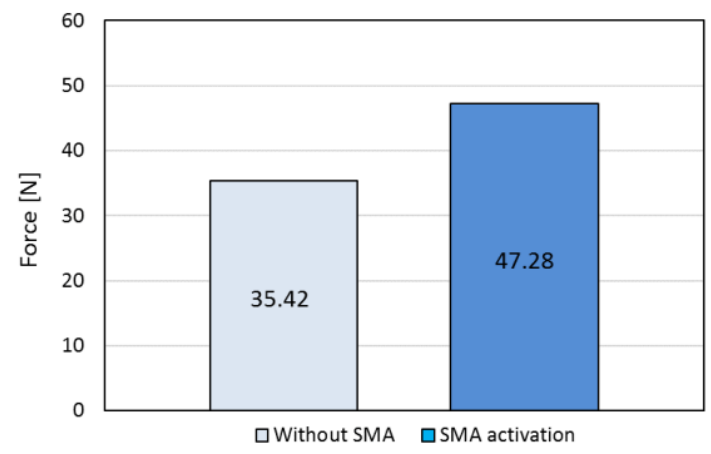

Fig. 18. Average force pulsation - side forces 


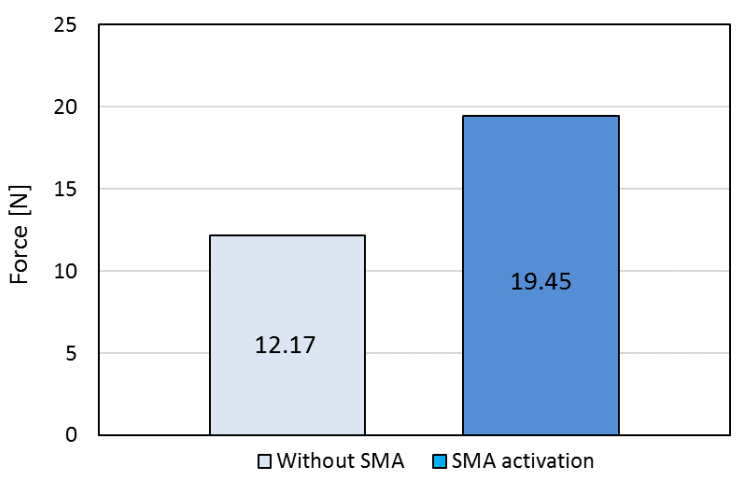

Fig. 19. Harmonics of the side forces $-\mathrm{I} h$ force pulsation

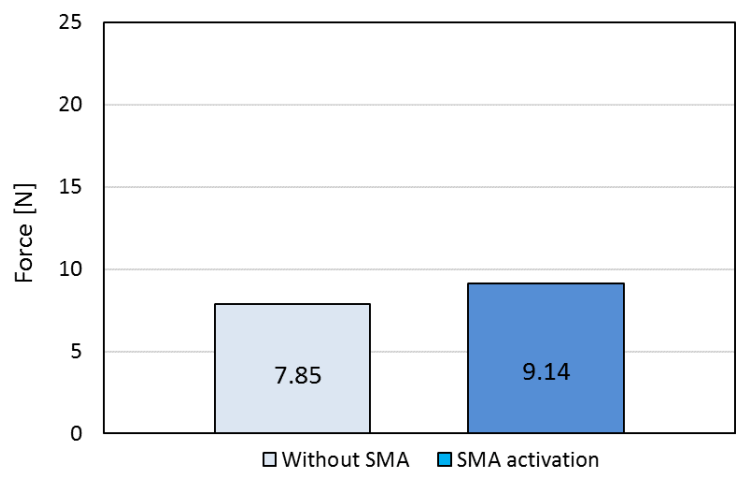

Fig. 20. Harmonics of the side forces - II h force pulsation

The key parameter affecting the safety of the structure is the time of the non-stationary state i.e. the time when the blade (rotor) changes its geometric features. The use of shape memory materials enables a geometric twist to be changed in a relatively long time compared to other active materials. The assumed full cycle of change defined as $10 \mathrm{~s}$ when the rotor was in a transient state showed no danger of losing stability but an increase in the harmonic components of the side force and propulsion torque values.

The correct selection of the main rotor construction parameters such as joint spacing, oscillation compensator, oscillation and deflection coefficients and Lock's number ensures structural stability and stops the uncontrolled growth of particularly non-harmonic loads which indicate a loss of stability and may lead to the occurrence of flatter and divergence phenomena. The phenomenon of instability itself, i.e. flatter and divergence was not analyzed. An example of incorrectly selected rotor design features is shown in the dynamic angle diagram below (Fig. 21).

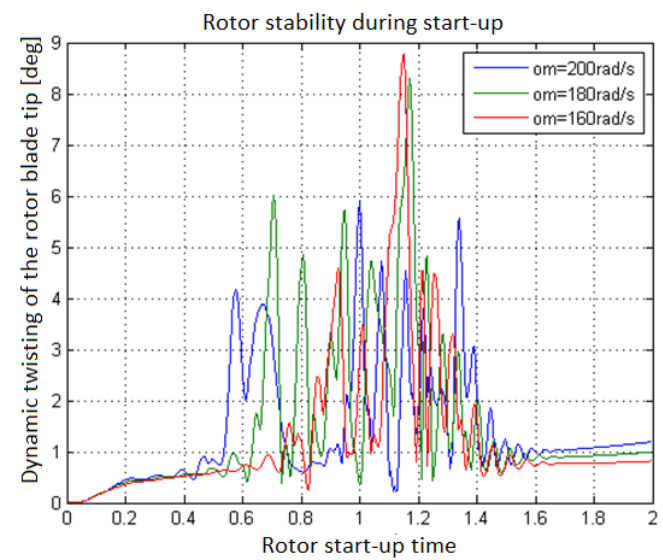

Fig. 21. Dynamic twist angle for the case of a rotor stability loss

\section{Conclusions}

The obtained results show that the application of active control systems of geometric features of the rotor does not significantly affect the stability of the rotor in transient states, i.e. between the state in which the actuators were not activated and the state of their full activation.

The parameters affecting the evaluation and selection of the propulsion unit were also analyzed to ensure a smooth regulation of the fuel flow to stabilize the fluctuations of the power required. The above results indicate that the selection of the drive unit, apart from a constant value, must take into account the pulsation values for both $\mathrm{I} h$ of rotation $(25 \mathrm{~Hz})$ and III $\mathrm{h}(75 \mathrm{~Hz})$ while maintaining the torsional stability of the drive system.

\section{Acknowledgements}

This work has been financed by the National Centre for Research and Development under the LIDER program. Grant Agreement No. LIDER/45/0177/L-9/17/NCBR/2018.

\section{Nomenclature}

AoA angle of atack

FEM finite element method

MBD multi body dynamics
OAT outside air temperature in Celsius degrees

PCA pitch control axis

SMA shape memory alloys

\section{Bibliography}

[1] ALQAHTANI, A., SHOKROLLAHIHASSANBAROUGH, F., WYSZYNSKI, M.L. Thermodynamic simulation comparison of AVL BOOST and Ricardo WAVE for HCCI and SI engines optimisation. Combustion Engines. 2015, 161(2), 68-72. https://doi.org/10.19206/CE-116893

[2] AMEDURI, S., CONCILIO, A. Morphing wings review: aims, challenges, and current open issues of a technology. Proceedings of the Institution of Mechanical Engineers, Part C: Journal of Mechanical Engineering Science. 2020. https://doi.org/10.1177/0954406220944423
[3] BAYRAMOĞLU, K., YILMAZ, S. Emission and performance estimation in hydrogen injection strategies on diesel engines. International Journal of Hydrogen Energy. 2021, 46(57), 29732-29744.

https://doi.org/10.1016/j.ijhydene.2020.08.135

[4] CARLUCCI, A.P., FICARELLA, A., LAFORGIA, D. et al. Supercharging system behavior for high altitude operation of an aircraft 2-stroke Diesel engine. Energy Conversion and Management. 2015, 101, 470-480.

https://doi.org/10.1016/j.enconman.2015.06.009 
[5] CARLUCCI, A.P., FICARELlA, A., TRUllO, G. Performance optimization of a two-stroke supercharged diesel engine for aircraft propulsion. Energy Conversion and Management. 2016, 122, 279-289.

https://doi.org/10.1016/j.enconman.2016.05.077

[6] CZYŻ, Z., SIADKOWSKA, K. Measurement of air flow velocity around the unmanned rotorcraft. 2020 IEEE 7th International Workshop on Metrology for AeroSpace (MetroAeroSpace), Pisa. 2020, 625-629.

https://doi.org/10.1109/MetroAeroSpace48742.2020.9160062

[7] DOPONA, M., FOXHALL, N., DUTZLER, C. 912iS fuel injected aircraft engine. SAE Technical Paper 2012-320049. 2012. https://doi.org/10.4271/2012-32-0049

[8] FORTINI, A., SUMAN, A., MERLIN, M. et al. Morphing blades with embedded SMA strips: an experimental investigation. Materials and Design. 2015, 85, 785-795. https://doi.org/10.1016/j.matdes.2015.07.175

[9] KALWARA, M., KUŹNIAR, M., ORKISZ, M. A rotating piston engine with electric generator in serial hybrid propulsion system for use in light aircraft. Combustion Engines. 2021, 187(4), 42-45. https://doi:10.19206/CE-141353

[10] KARDACH, M., GALANT, M., FUĆ, P. Analysis of the ecological effectiveness of passenger transport by jets of various sizes. Combustion Engines. 2019, 178(3), 252-256. https://doi:10.19206/CE-2019-344

[11] KOZAK, M., MERKISZ, J., BIELACZYC, P. The effect of fuel properties on exhaust emissions from diesel passenger car. Silniki Spalinowe. 2005, 1(120), 19-30. https://doi.org/10.19206/CE-117408

[12] LACHENAL, X., DAYNES, S., WEAVER, P.M. Review of morphing concepts and materials for wind turbine blade applications. Wind Energy. 2013, 16, 283-307. https://doi.org/10.1002/we.531

[13] ORKISZ, M., KUŹNIAR, M. 3E - a new paradigm for the development of civil aviation. Combustion Engines. 2020, 181(2), 3-10. https://doi:10.19206/CE-2020-201

[14] PANKONIEN, A.M. Smart material wing morphing for unmanned aerial vehicles. University of Michigan. 2015. https://deepblue.lib.umich.edu/handle/2027.42/111533

[15] PRAJIT, R., SRIVATSAN, S., SATHWIK, V. Smart materials - a view towards SMA. SAE Technical Paper 2014-28-0045. 2014. https://doi.org/10.4271/2014-28-0045

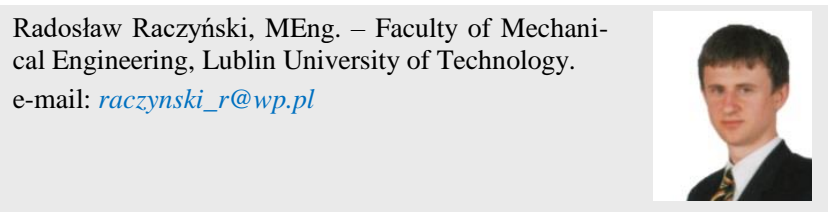

Karol Ścisłowski, MEng. - Faculty of Mechanical Engineering, Lublin University of Technology. e-mail: k.scislowski@pollub.pl
[16] ROY, M.M., TOMITA, E., KAWAHARA, N. et al. An experimental investigation on engine performance and emissions of a supercharged $\mathrm{H} 2$-diesel dual-fuel engine. International Journal of Hydrogen Energy. 2010, 35, 844853. https://doi.org/10.1016/j.ijhydene.2009.11.009

[17] SAEED, A.S., YOUNES, A.B., ISLAM, S. et al. A review on the platform design, dynamic modeling and control of hybrid UAVs. International Conference on Unmanned Aircraft Systems. ICUAS, 2015, 806-815. https://doi.org/10.1109/ICUAS.2015.7152365

[18] SARKAR, P., RACZYNSKI, R. Gurney flap force calculations. In: Doerffer, P., Barako,s G.N., Luczak M.M. (Eds.) Recent Progress in Flow Control for Practical Flows. Springer. 2017, 126-135. https://doi.org/10.1007/978-3-319-50568-8

[19] SEHRA, A.K., WHITLOW, W. Propulsion and power for 21st century aviation. Progress in Aerospace Sciences. 2004, 40(4-5), 199-235.

https://doi.org/10.1016/j.paerosci.2004.06.003

[20] SIADKOWSKA, K. Aerodynamic measurement of the rotor blade for aviation application. 2020 IEEE 7th International Workshop on Metrology for AeroSpace (MetroAeroSpace). Pisa, 2020, 610-614.

https://doi.org/10.1109/MetroAeroSpace48742.2020.9160131

[21] SIADKOWSKA, K., CZAJKA, B., ŚCISŁOWSKI, K. et al. Analysis of propulsion units dedicated to test stands for aviation systems. Combustion Engines. 2021, 185(2), 39-43. https://doi.org/10.19206/CE-139405

[22] SIADKOWSKA, K., MAJCZAK, A., BARAŃSKI, G. Studying a construction of pistons for the aircraft CI engine. Combustion Engines. 2017, 168(1), 161-167. https://doi.org/10.19206/CE-2017-126

[23] SIADKOWSKA, K., RACZYNSKI, R., WENDEKER, M. Numerical analysis of the rotor in the co-simulation methodology. IOP Conference Series: Materials Science and Engineering. 2019, 710(012009). https://doi.org/10.1088/1757-899X/710/1/012009

[24] SOFLA, A.Y.N., MEGUID, S.A., TAN, K.T. et al. Shape morphing of aircraft wing: status and challenges. Materials and Design. 2009, 31, 1284-1292. https://doi.org/10.1016/j.matdes.2009.09.011

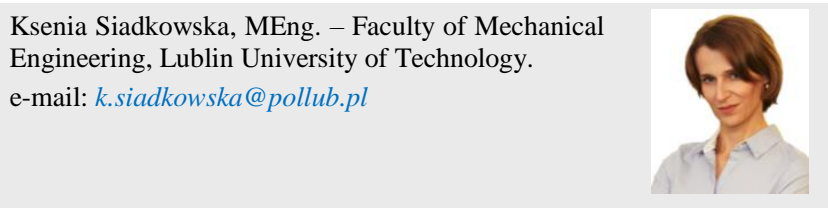

Prof. Mirosław Wendeker, DSc., DEng. - Faculty of Mechanical Engineering, Lublin University of Technology.

e-mail:m.wendeker@pollub.pl 